\title{
EFFECT OF SOCIO-ART WORKING GROUP THERAPY IN REDUCING THE SYMPTOMS OF HALLUCINATIONS IN COMMUNITY HEALTH CENTER
}

\author{
Retno Lestari ${ }^{*}$, Ahsan \\ Department of Nursing, University of Brawijaya
}

\author{
Accepted: 1 September 2017 \\ *Correspondence: \\ Retno Lestari \\ Department of Nursing, Faculty of Medicine, University of Brawijaya \\ Jl. Veteran-Malang, Jawa Timur, 65145. \\ Email: retno.lestari98@gmail.com
}

Copyright: (C) the author(s), YCAB publisher and Public Health of Indonesia. This is an open-access article distributed under the terms of the Creative Commons Attribution Non-Commercial License, which permits unrestricted non-commercial use, distribution, and reproduction in any medium, provided the original work is properly cited.

ABSTRACT

Background: Schizophrenia is a chronic illness with considerable impact on individuals and their families. One of the symptoms of schizophrenia is hallucination. The treatment goals are reducing the symptoms and maintaining the recovery from the effects of illness.

Objective: This study aimed to analyze the effect of socialization and art-working group therapy in reducing the symptoms of hallucinations.

Methods: This study used a pre-experimental design with one-group pretest-posttest involved 60 patients aged between 12 and 55 years diagnosed with schizophrenia in the Community-Integrated Health Care in East Java. The Symptoms of Hallucinations Checklist was used to assess the hallucination symptoms. Data were analyzed using Wilcoxon signed rank test.

Results: Findings showed that there was a statistically significance difference between pretest and posttest score after the socialization and art-working group therapy with $\mathrm{p}$-value $0.000(\mathrm{p}<0.05)$.

Conclusion: Socialization and art-working group therapy had a significant effect in reducing the symptoms of hallucinations in patients with schizophrenia.

Key words: Socialization, art-working, group therapy, and hallucinations

\section{BACKGROUND}

Schizophrenia is a chronic illness with considerable impact on individuals and their families. ${ }^{1}$ There are two main symptoms in schizophrenic patients, namely positive and negative symptoms. The 'positive' symptoms of schizophrenia include hallucinations, such as hearing voices; and delusions, such as paranoid thoughts. Additionally, the 'negative' symptoms consist of feeling restless, attention disorder, and reduction in speech content. ${ }^{1}$

The treatment goals of schizophrenia are reducing the symptoms and maintaining the recovery from the effects of illness. Antipsychotic medication reduces the symptoms of schizophrenia; 
however the problem is still arising when many people have issues in medication adherence. It increases the risk of relapse, self-harm and re-hospitalization. Meanwhile, psychotherapy and social interventions are used in combination with pharmacotherapy to improve the health of schizophrenic patients. ${ }^{1-3}$

The combination of socialization and art-working group therapy provides several goals. The socialization program itself increases patients' involvement in activity of discussion in a team. Additionally, during discussion, the patients make several art projects based on the topic provided by health professionals. Patients with hallucinations could have a positive effect from an environment that provides companionship, so they would not feel alone and maintain their functional abilities. $^{4}$ Therefore, this study aimed to analyze the effect of socialization and art- working group therapy in reducing the symptoms of hallucinations.

\section{LITERATURE REVIEW}

Schizophrenia has two main symptoms, the positive symptoms and the negative symptoms. The 'positive' symptoms include hallucinations, and delusions. Hallucinations often experienced as the absence of external stimuli, which patients have social isolation and feel frightened with other people. This condition impacts on patients' behavior and functional capacity. Patients have loss abilities to engage with people in workplace and other activities (see Figure 1). ${ }^{5}$ The 'negative' symptoms consist of feeling restless, attention disorder, and speech impairment. The combination of socialization and artworking group therapy is provided to reduce the symptoms of hallucinations in patients with schizophrenia.

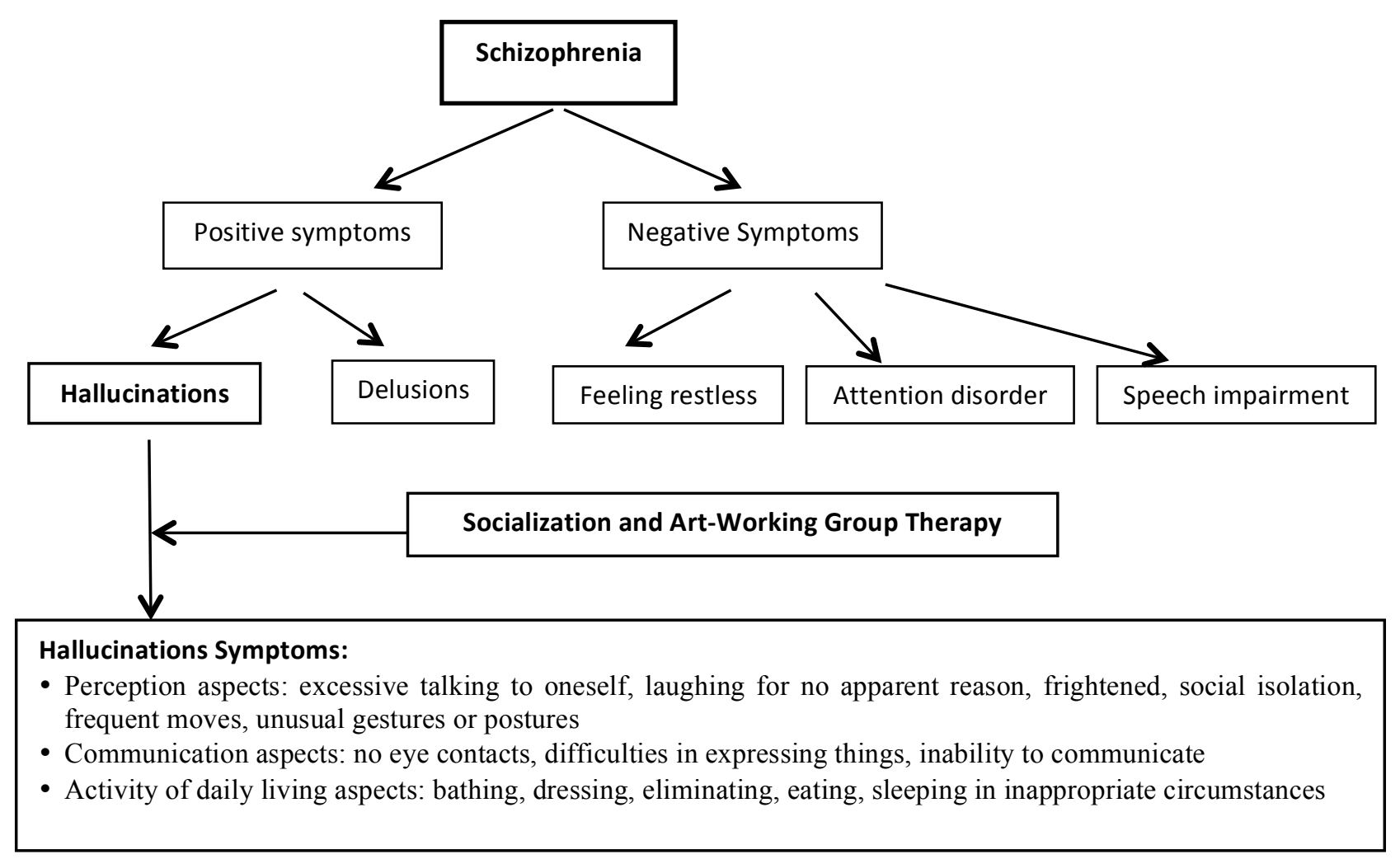

Figure 1. The Conceptual Framework 


\section{METHODS}

Study design

This was a pre-experimental design with one group pretest-posttest to analyze the effect of socialization and art-working group therapy in reducing the symptoms of hallucinations.

\section{Population and sample}

Sixty patients from five villages in a Community-Integrated Health Care in East Java were included using purposive sampling. The inclusion criteria were: patients with schizophrenia and showed positive symptoms of hallucinations, such as hearing voices. Respondents who were not cooperative and either family did not give consent for therapy were excluded from the study. The study was conducted between December and January 2016.

\section{Instruments}

The Symptoms of Hallucinations Checklist developed by the researcher was used to measure the symptoms of hallucinations in this study. The instrument consisted of 25 items, namely the aspects of perceptions (11 items), communication (6 items), and daily living activities ( 8 items). The reliability (Cronbach alpha) of the instrument was 0.941 .

\section{Intervention}

This program was held in a place where health professionals often used for a meeting or therapy, called as "Bengkel Artis". There were four sessions, which was scheduled once every two weeks.

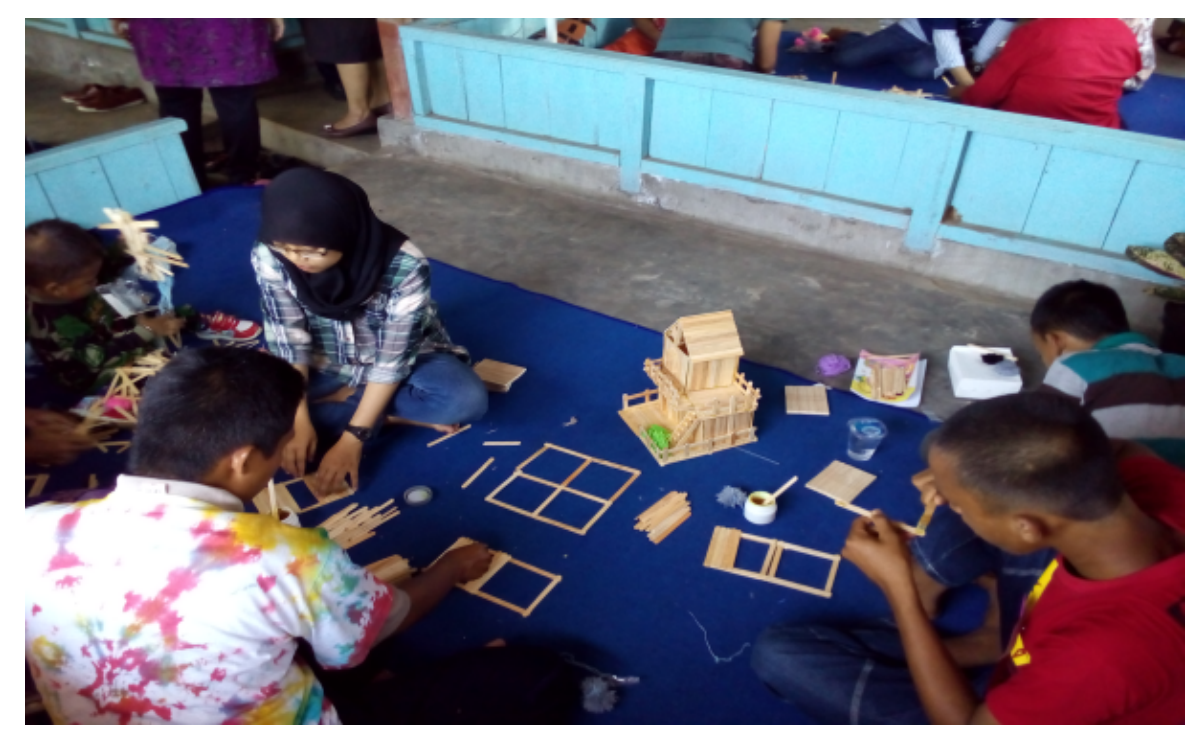

Figure 2. Respondents were making "a miniature of house"

The therapy of socialization and artworking group therapy was performed by the researchers assisted by health professionals and cadre for approximately 1 hour. It consisted of: 1) Familiarizing respondents to all groups by facilitating clients to introduce themselves and describing their appearances and hobbies. The goals for the first session was to identify the characteristics of respondents during session and producing a simple art, "Drawing my favorite things", 2) Describing "my journey" to all groups. The goals for this session was to introduce the benefits of conversation with other people and producing "a story book" using flannelled materials, 3) Introducing how to ask for requests from other people. This 
session aimed to familiarize respondents in making requests from their families, friends or neighbors. When making requests, the respondents were asked to make an eye contact, sit next to their friends and explained their requests. During this session, in order to improve their conversation, "a miniature of house" from ice cream sticks was produced (Figure 2), and 4) Engaging respondents to other group member from different village. The last session aimed to facilitate each respondent to other group member by describing his/her art-working productions. In this session, the researchers observed their abilities to communicate and the symptoms presence of hallucinations.

\section{Data analysis}

In data analysis, mean and standard deviation were described using SPSS version 20. Wilcoxon Signed Ranks test was used to find any significant difference of hallucination symptoms exist among the pre and post therapy score.

\section{Ethical consideration}

Ethical approval was obtained from the Health Research Ethic Committee, Faculty of Public Health, Airlangga University on April 2016 (No: 152-KPK). A written approval from the site including families was also obtained. Informed consent was performed in each participant.

\section{RESULTS}

\section{Characteristics of Respondents}

As shown in the Table 1, the majority of respondents aged over 20 years as many as $55(91.7 \%)$ people, with $40 \quad(66.7 \%)$ females and $20(33.3 \%)$ males. Of all respondents, $61.7 \%$ reported duration of illness less than 5 years.

Table 1. Characteristics of respondents based on age, gender, and duration of illness

\begin{tabular}{|l|c|c|}
\hline \multicolumn{1}{|c|}{ Characteristics of respondents } & $\mathbf{n}$ & $\mathbf{\%}$ \\
\hline Age & & \\
\hline$<20$ years & 5 & 8.3 \\
\hline$>20$ years & 55 & 91.7 \\
\hline Total & $\mathbf{6 0}$ & $\mathbf{1 0 0}$ \\
\hline Gender & & \\
\hline Female & 40 & 66.7 \\
\hline Male & 20 & 33.3 \\
\hline Total & $\mathbf{6 0}$ & $\mathbf{1 0 0}$ \\
\hline Duration of illness & 37 & 61.7 \\
\hline$<5$ years & 23 & 38.3 \\
\hline$>5$ years & $\mathbf{6 0}$ & $\mathbf{1 0 0}$ \\
\hline Total & & \\
\hline
\end{tabular}

Difference in hallucination symptoms between pretest and posttest

The study aimed to analyze the effect of socialization and art-working group therapy in reducing the symptoms of hallucinations. The instrument was scored by both the health professionals from the Community Integrated Health Care and the researchers. The results of the pre and post therapy of hallucinations symptoms scores are shown below: 
Table 2. Difference in hallucination symptoms between pretest and posttest using Wilcoxon signed rank test $(n=60)$

\begin{tabular}{|l|l|l|}
\hline \multicolumn{1}{|c|}{ Hallucinations Symptoms } & Mean \pm SD & P-value \\
\hline Perceptions & & \\
\cline { 1 - 2 } Pretest & $33.27 \pm 1.351$ & \\
\cline { 1 - 2 } Posttest & $25.23 \pm 1.267$ & \multirow{2}{*}{$0.000^{*}$} \\
\hline Communication & $17.18 \pm 0.813$ & \\
\hline Pretest & $14.20 \pm 1.482$ & \\
\hline Posttest & & \\
\hline Daily Living Activities & $20.87 \pm 0.929$ & \\
\hline Pretest & $20.53 \pm 0.873$ & \\
\hline Posttest & \\
\hline
\end{tabular}

Wilcoxon Signed Ranks Test showed p-value $0.000(<0.05)$. It can be concluded that there was a statistically significance difference between pretest and posttest score after the socialization and artworking group therapy.

\section{DISCUSSION}

The key principles in managing hallucinations are promoting a good environment, which supports behavior change among schizophrenic patients. Therefore, it will optimize medication adherence and promote the abilities of person's life. ${ }^{6}$ Long term group therapy is needed to improve better effects on quality of life, medication adherence and functional abilities. ${ }^{7}$ However, schizophrenic patients should be always motivated for group work therapy.

Combining the therapy of socialization and art-working group activities could promote better conversations between respondents and provide external stimuli to reduce the symptoms of hallucinations. The program of art therapy has benefits to make a person understand them better and giving powerful feelings. ${ }^{8}$ Art therapy including physical activity could significantly increase the level of cognitive, memories, mood in schizophrenia. Activities in the group also have the potential function to improve quality of life for people with schizophrenia in two aspects, namely physical and psychological healths. ${ }^{9-11}$

Art therapy could also be effective in promoting better behavior in schizophrenia patients who were not responding to medications. ${ }^{11,12}$ Further, art therapy has specific therapeutic benefits for respondents, such as focusing on what they were doing, learning to responds well, using gestures appropriately, following rules during activities, interacting with others and promoting independence. ${ }^{13,14}$ Through community health center, respondents who live in rural areas have facilitators to undertake and create any other art activities to improve patients' well being. Studies showed that art activities in communities could promote better environment compared to activities which usually held in hospital. ${ }^{15}$ Moreover, respondents stated that art activities could reduce feelings of stress, enhance selfesteem and improve decision making abilities. $^{16}$

This study provides group activities that took place on a fortnightly basis in four sessions. Facilitators of these groups were recruited from nurses and health cadre in community health center to encourage respondents to follow the therapy. After the therapy session, each respondent had opportunities to explore their thoughts and feelings related to their 
abilities during activities and also level of hallucination symptoms. While standard care was also provided by community health center, these kinds of activities could improve their daily routines and respondents agreed to undertake art activities at home.

This study did not use the intervention with pre-post test with control group to enhance validity of the study. Study respondents were limited in size and recruited from community integrated health center in five villages from geographically isolated area, so the researchers had to pick them up to the health center to do the activities. Nevertheless, the results were sufficiently promising to justify for further research.

\section{CONCLUSION}

People living with schizophrenia need a long-term treatment, which they may not follow their treatment properly and have a relapse. To reduce the risk of relapse, selfharm and re-hospitalization, psychotherapy and social interventions are used in combination with pharmacotherapy to improve the health of schizophrenic patients. This study revealed that the combination of socialization and artworking group therapy reduced the symptoms of hallucinations. In addition, patients with schizophrenia also have a good environment providing companionship in order not to feel alone and maintain their functional abilities.

\section{ACKNOWLEDGEMENTS}

We would like to express our special thanks to all of the participants for participating in this program. We also received support from CommunityIntegrated Health Center in East Java and School of Nursing, Medical Faculty, University of Brawijaya, to conduct this research.

\section{REFERENCES}

1. Mortan PO, SÜTcÜ PST, KÖSe PGG. A pilot study on the effectiveness of a group-based cognitive-behavioral therapy program for coping with auditory hallucinations. Turk Psikiyatri Dergisi. 2011;22(1):26.

2. Sommer IEC, Slotema CW, Daskalakis ZJ, Derks EM, Blom JD, van der Gaag M. The treatment of hallucinations in schizophrenia spectrum disorders. Schizophrenia bulletin. 2012;38(4):704-714.

3. Pareek B, Kalia R. Factors affecting non-compliance to psychotropic drugs of patients with psychosis as perceived by their family members attending the psychiatric outpatient department at selected hospital, Mangalore. Nurs Midwifery Res J. 2013;9(2):56-62.

4. Gabrovšek VP. Inpatient group therapy of patients with schizophrenia. Psychiatria Danubina. 2009;21(1):67-72.

5. Ford JM, Morris SE, Hoffman RE, et al. Studying hallucinations within the NIMH RDoC framework. Schizophrenia Bulletin. 2014;40(Suppl_4):S295-S304.

6. Thomas N, Hayward M, Peters E, et al. Psychological therapies for auditory hallucinations (voices): current status and key directions for future research. Schizophrenia bulletin. 2014;40(Suppl_4):S202S212.

7. Pesek MB, Mihoci J, Medved K, Solinc NP. Long term groups of patients with psychosis: physical activity and medical treatment. Psychiatr Danub. 2011;23(1):149154.

8. Crawford MJ, Killaspy $\mathrm{H}$, Kalaitzaki E, et al. The MATISSE 
study: a randomised trial of group art therapy for people with schizophrenia. BMC psychiatry. 2010;10(1):65.

9. Stubbs B, Soundy A, Probst M, et al. The assessment, benefits and delivery of physical activity in people with schizophrenia: a survey of members of the International Organization of Physical Therapists in Mental Health. Physiotherapy Research International. 2014;19(4):248-256.

10. Gorczynski P, Faulkner G. Exercise therapy for schizophrenia. The Cochrane Library. 2010.

11. Crawford MJ, Killaspy H, Barnes TRE, et al. Group art therapy as an adjunctive treatment for people with schizophrenia: multicentre pragmatic randomised trial. $B m j$. 2012;344:e846.

12. Bitonte RA, De Santo M. Art therapy: an underutilized, yet effective tool. Mental Illness. 2014;6(1).

13. Kelly S, Davies L, Harrop D, McClimens A, Peplow D, Pollard
$\mathrm{N}$. Reviewing art therapy research: a constructive critique. 2015.

14. Murray M, Gray R. Health psychology and the arts: A conversation. Journal of health psychology. 2008;13(2):147-153.

15. Stuckey HL, Nobel J. The connection between art, healing, and public health: A review of current literature. American journal of public health. 2010;100(2):254263.

16. Hughes EG, da Silva AM. A pilot study assessing art therapy as a mental health intervention for subfertile women. Human reproduction. 2011;26(3):611-615.

Cite this article as: Lestari $\mathrm{R}$, Ahsan. Effect of Socio-Art Working Group Therapy in reducing the Symptoms of Hallucinations in Community Health Center. Public Health of Indonesia 2017;3(3):124-130 